\title{
Tractor-Implement Tillage Depth Control Using Adaptive Neuro-Fuzzy Inference System (ANFIS)
}

\author{
Aristide Timene $^{1, *}$, Ndjiya Ngasop ${ }^{2}$, Haman Djalo $^{1}$ \\ ${ }^{1}$ Department of Physics, Faculty of Sciences, University of Ngaoundere, Cameroon \\ ${ }^{2}$ Department of Electrical Engineering, Energy and Automation, National School of Agro-Industrial Sciences, \\ University of Ngaoundere, Cameroon \\ Received 20 April 2021; received in revised form 10 May 2021; accepted 11 May 2021 \\ DOI: https://doi.org/10.46604/peti.2021.7522
}

\begin{abstract}
This study presents a design of an adaptive neuro-fuzzy controller for tractors' tillage operations. Since the classical controllers allows plowing depth errors due to the variations of lands structure, the use of the combined neural networks and fuzzy logic methods decreases these errors. The proposed controller is based on Adaptive Neuro-Fuzzy Inference System (ANFIS), which permits the generation of fuzzy rules to cancel the nonlinearity and disturbances on the implement. The design and simulations of the system, which consist of a hitch-implement mechanism, an electro-hydraulic actuator, and a neuro-fuzzy controller, are conducted in SolidWorks and MATLAB software. The performance of the proposed controller is analyzed and is contrasted with a Proportional Integral Derivative (PID) controller. The obtained results show that the neuro-fuzzy controller adapts perfectly to the dynamics of the system with rejection of disturbances.
\end{abstract}

Keywords: tractor-implement, plowing depth, neuro-fuzzy controller

\section{Introduction}

On farmlands, a tractor's electro-hydraulic hitch system lowers, holds, or lifts implements into the ground depending on the desired working depth [1]. To command the hydraulic hitch system, modern tractors are supplied with position control and draft force control system. However, variations in soil conditions (e.g., texture and organic matter) causes plowing depth errors. This situation directly decreases root penetration and plant growth.

For a better approximation of land structures, it is recommended to mix the position and draft control [2-3]. In [2], a combined position-draft control was used to adjust the tillage depth of the implement. In their study, the participation ratio of the position target and the draft force target are mixed before being processed for regulation. Then, a fuzzy controller sends an appropriate signal to the electro-hydraulic system to cancel the plowing depth error. This strategy makes it possible to limit the changes in plowing depth due to the changes in soil resistance. Shafaei, Loghavi, and Kamgar [3] also prove the capacity of fuzzy controller to decrease plowing depth errors, driving wheel slip, and fuel consumption in tillage operations. Furthermore, the fuzzy logic controller is also used in [4] to compensate nonlinearities and reduce pressure fluctuation in tractor's hydraulic hitch.

If fuzzy logic is often used in the control of the electro-hydraulic system of the tractor to overcome nonlinearities, it nevertheless has limits, in particular on the accuracy of the information expressed in natural language after mixing position and draft. To overcome this drawback, the current trend is to use hybrid architectures to take advantage of fuzzy logic and neural networks. The use of Adaptive Neuro-Fuzzy Inference System (ANFIS) offers the possibility of modeling a priori knowledge and linguistic decision rules obtained by experts in the field [5-6].

* Corresponding author. E-mail address: aristidetimene @yahoo.com 
Indeed, much research has proven the usefulness of the ANFIS method, developed by Jang [7] for the control of systems. The neuro-fuzzy controller was used in [8] to ensure that one leg of a quadruped robot follows the desired trajectory. In [9], the neuro-fuzzy controller was used to stabilize the climatic variables inside greenhouse system at required levels for crops development. An adaptive neuro-fuzzy controller was designed in [10], for the speed control of permanent magnet synchronous motor. The proposed controllers were satisfactory in terms of easy settling time, zero peaks overflow, and high robustness.

In this work, a controller combining two intelligent techniques (fuzzy logic and neural networks) is designed to decrease tractors' plowing depth errors. This study comprises six sections. First, the hitch-implement model is presented in section 2. Then, section 3 describes the electro-hydraulic actuator and section 4 presents the proposed controller. To show the effectiveness of the enhanced neuro-fuzzy control strategy, the simulations examples are provided and commented in section 5. Finally, a concluding summary ends the study.

\section{Modelling of Hitch-Implement Mechanism}

A tractor's three-point hitch mechanism is modeled in SolidWorks software. The kinematics of the up and down movement of the system is described in [11]. The common mechanism of the system is shown in Fig. 1. The tractor model is category 2, which has a maximum lifting capacity of $3546 \mathrm{Kg}$ with a power of $90 \mathrm{hp} \mathrm{[12].}$

The dimensions of the model are listed in Table 1. For a more realistic simulation, the MATLAB/Simscape Multibody model of the tractor's hitch system is imported from SolidWorks software with the physical properties to calculate the movement. The MATLAB model of the hitch-implement mechanism is given in Fig. 2.

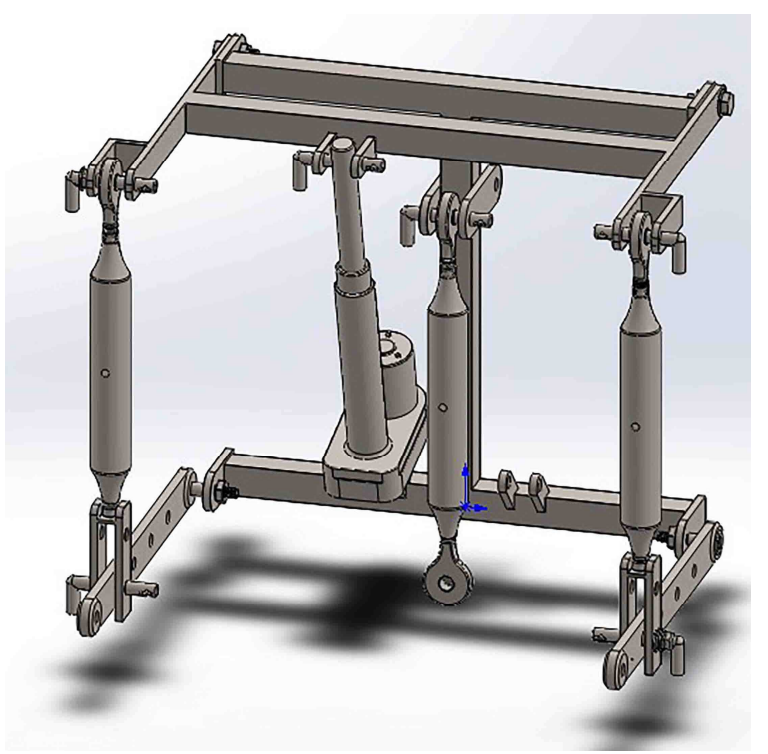

Fig. 1 Computer-Aided Design (CAD) model of the tractor's three-point hitch mechanism

Table 1 Parameters of the three-point hitch linkages

\begin{tabular}{|c|c|}
\hline Part name & Measure \\
\hline Lift arm length & $295 \mathrm{~mm}$ \\
\hline Lower link length & $946 \mathrm{~mm}$ \\
\hline Lift rod length & $765 \mathrm{~mm}$ \\
\hline Vertical length from lift arm pivot point to upper link pivot point & $130 \mathrm{~mm}$ \\
\hline Upper link length & $650 \mathrm{~mm}$ \\
\hline Mast Height & $610 \mathrm{~mm}$ \\
\hline Vertical length from upper link pivot point to lower link pivot point & $460 \mathrm{~mm}$ \\
\hline External lift cylinder length & $380-560 \mathrm{~mm}$ \\
\hline Stroke of the cylinder & $180 \mathrm{~mm}$ \\
\hline
\end{tabular}




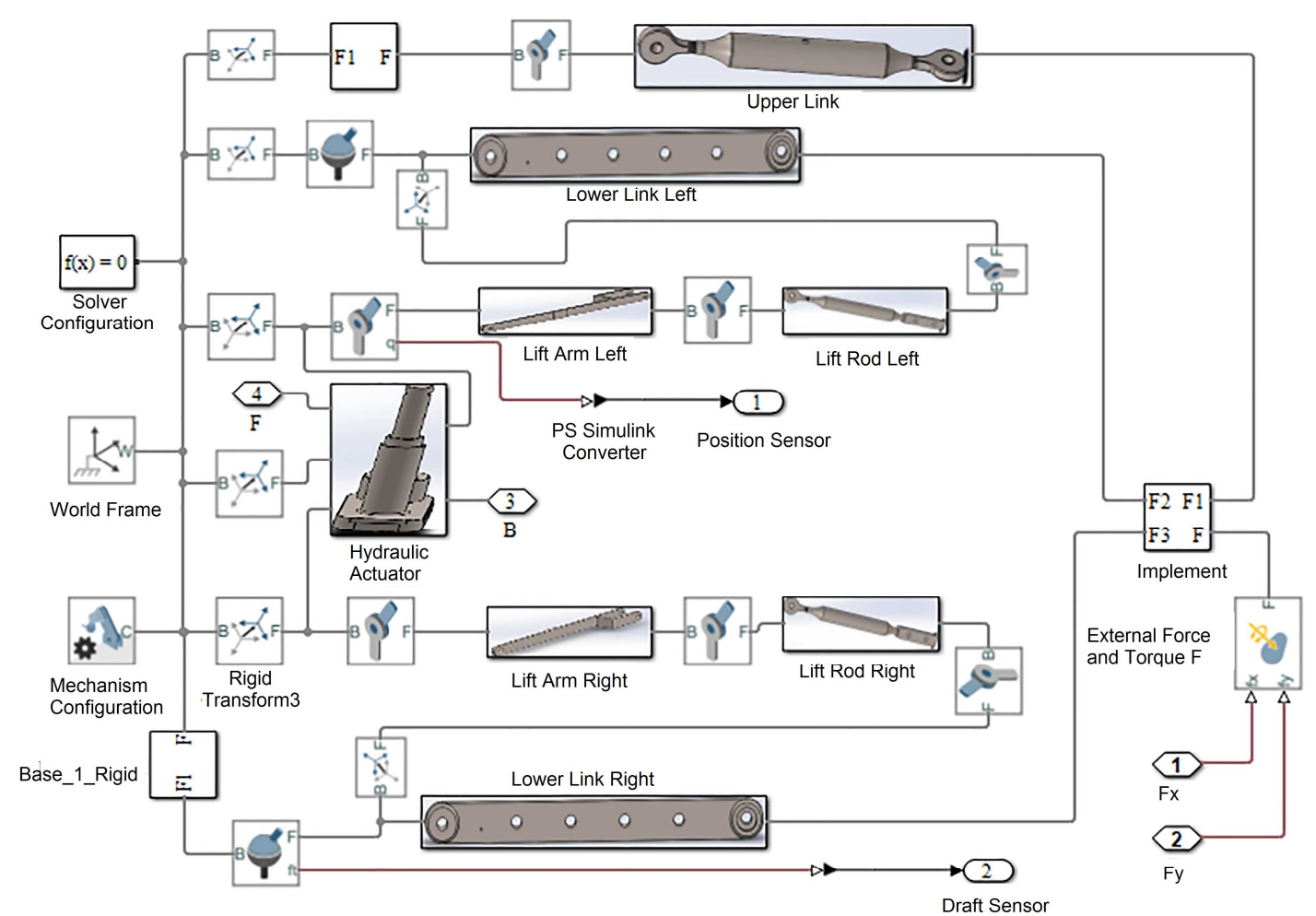

Fig. 2 Hitch-implement mechanism in MATLAB

In this work, two implement have been used: chisel plow and moldboard plow. The parameters listed in Table 2 are provided from the data in [13]. The force applied to the implement on the ground is the disturbance of the system. It is expressed by [13]:

$$
F=T_{s} \times\left(A+B \times V+C \times V^{2}\right) \times W_{e} \times H_{d}
$$

where $F$ is the implement draft $(\mathrm{N}) ; T_{s}$ characterizes a dimensionless soil texture adjustment parameter for a category of soil $s$; $A, B$, and $C$ are machine specific parameters; $V$ is the tractor field speed $(\mathrm{km} / \mathrm{h}) ; W_{e}$ is the machine width (m) or number of rows; $H_{d}$ is the tillage depth $(\mathrm{cm})$.

Table 2 Parameters of implements and field operations

\begin{tabular}{|c|c|c|}
\hline Parameters & Chisel plow & Moldboard plow \\
\hline Plowing depth $(\mathrm{cm})$ & 30 & 10 \\
\hline Weight $(\mathrm{kg})$ & 380 & 200 \\
\hline A & 107 & 116 \\
\hline B & 6.3 & 0 \\
\hline C & 0 & 2.3 \\
\hline Soil type & clay & fine \\
\hline Working width $(\mathrm{m})$ & 2.1 & 1.04 \\
\hline Tractor speed $(\mathrm{km} / \mathrm{h})$ & 7 & 5 \\
\hline Draft force $(\mathrm{N})$ & 8095 & 2429 \\
\hline Draft range $(\%)$ & 50 & 40 \\
\hline
\end{tabular}

\section{Modelling of Hydraulic Actuator}

The actuator of the tractor is its electro-hydraulic system (Fig. 3), which allows the movement of hitch-implement mechanism. It consists of three main parts, namely the hydraulic pump, proportional valve, and the cylinder. The pump is operated by the tractor engine running at $1500 \mathrm{rpm}$. It provides a flow rate of $40 \mathrm{l} / \mathrm{min}$. A pressure relief valve assembled on the main distribution block limits the pressure to 194 bars. The two-module servo valve, type BOSCH EHR5 [14], directs the flow of fluid from the pump to the cylinder. Ports B and F are the actuator outputs to the hitch-implement mechanism. 
According to the manufacturer [14], the lifting valve control signal must be within an operating range of 1 to 3.35 A and the lowering valve control signal must be within an operating range of -1 to $-3.35 \mathrm{~A}$. To lift the implement, a positive signal is sent to the solenoid of the valve. Likewise, a negative signal is sent to the solenoid of the valve to lower the implement. The cylinder has a total stroke of $180 \mathrm{~mm}$. Its base is fixed on the main frame of the tractor, and its rod is on the lift arm. The position of the lift arm measured by a sensor is an input to the controller. The overall diagram of the tractor's tillage depth control system is shown in Fig. 4.

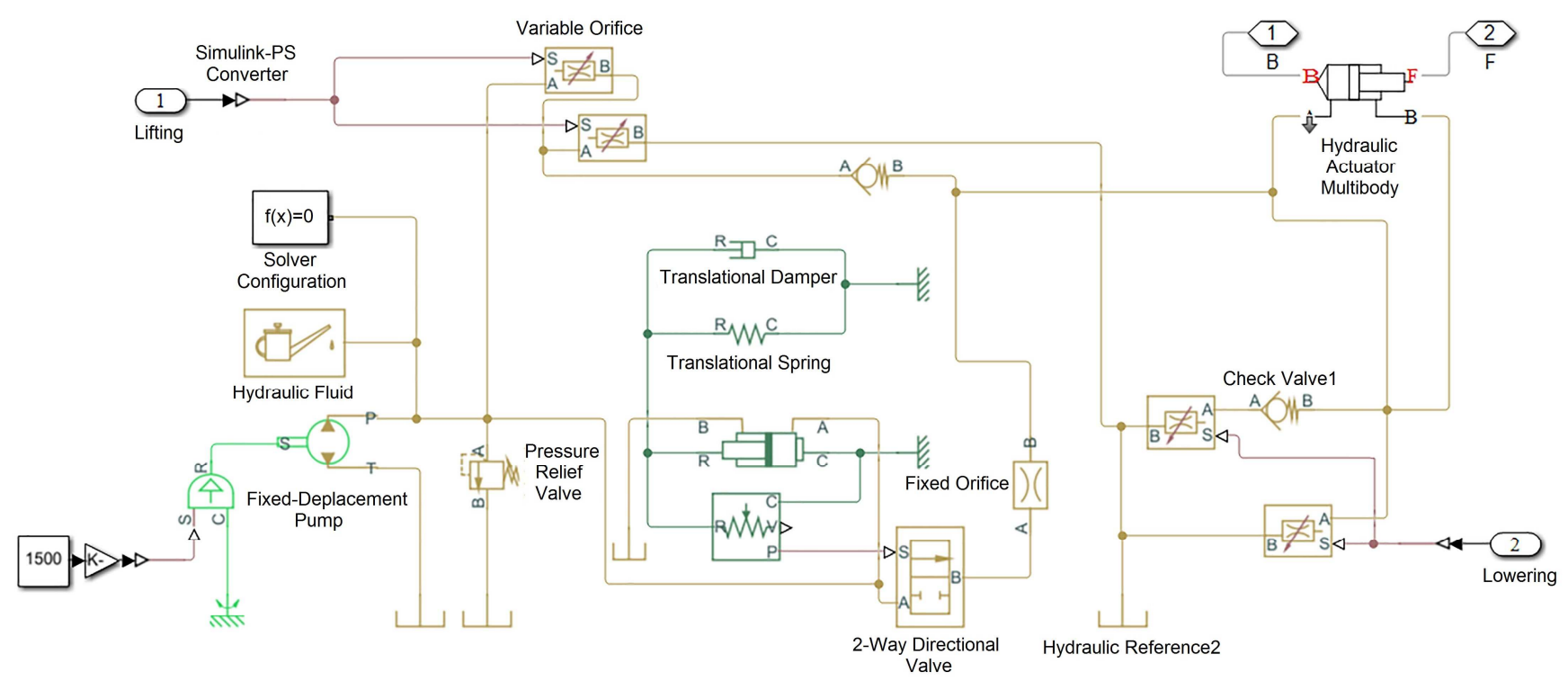

Fig. 3 Electro-hydraulic actuator in MATLAB/Simscape Fluids

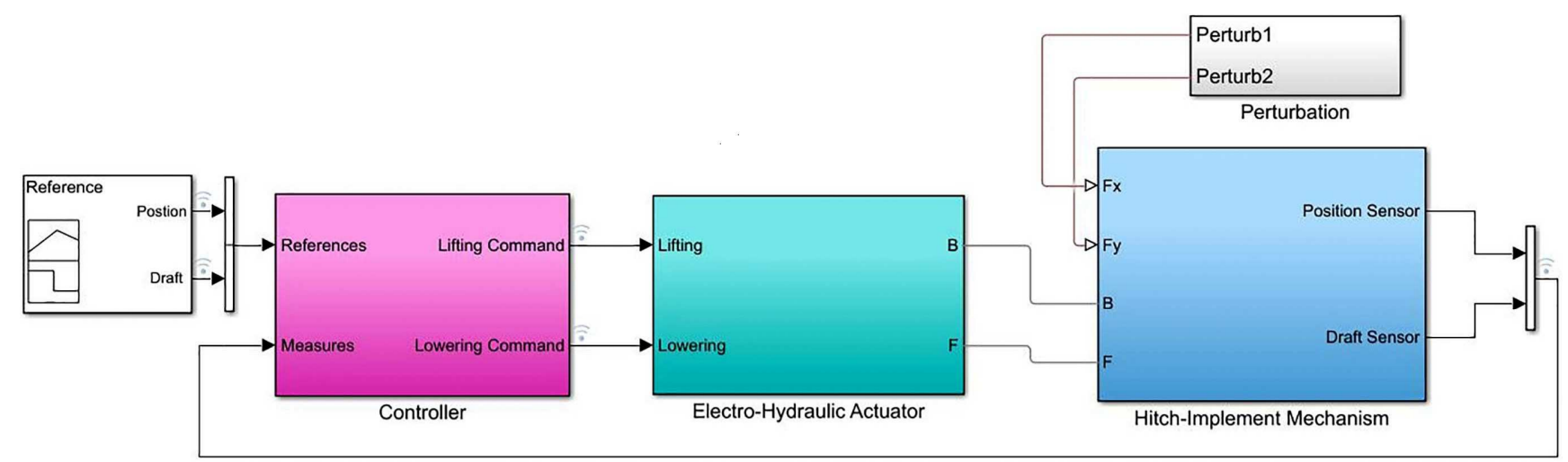

Fig. 4 Block diagram of the tillage depth control system

\section{Design of Controller}

\subsection{Mixed position-draft control strategy}

The combination of the position control and draft control allows dual goals, including tillage depth and tillage resistance. The target of position control is the depth parameter. The depth deviation is written as:

$$
e=H_{d}-H_{m}
$$

where $e$ is the error in depth, $H_{d}$ is the desired depth, and $H_{m}$ is the measured depth.

The draft control is used to modify tillage depth according to the soil resistance, using Eq. (1):

$$
H_{d}=\frac{F}{T_{s} \times\left(A+B \times V+C \times V^{2}\right) \times W_{e}}
$$


The depth deviation can be expressed by using Eq. (2):

$$
e=\frac{F_{d}-F_{m}}{T_{s} \times\left(A+B \times V+C \times V^{2}\right) \times W_{e}}
$$

where $e$ is the error in depth, $F_{d}$ is the desired draft force, and $F_{m}$ is the measured draft force.

Here, the participation ratio of the position target and the draft is adjusted according to the mix coefficient (M) proposed in [2]. The tillage depth deviation in the mixed control can be written as follows:

$$
e=\left[\frac{F_{d}-F_{m}}{T_{s} \times\left(A+B \times V+C \times V^{2}\right) \times W_{e}}\right] M+\left(H_{d}-H_{m}\right)(1-M)
$$

when $\mathrm{M}=0$, the control mode is position; when $\mathrm{M}=1$, the mode is draft control; when $0<\mathrm{M}<1$, the control mode is mixed.

The schematic diagram of the proposed controller is illustrated in Fig. 5. The user from the tractor panel enters the parameters of the desired depth $H_{d}$, coefficient $M$, tractor speed $V$, and type of implement. In the hitch-implement mechanism, the signals are measured by a force sensor and a position sensor. The data acquisition and calculation module collects the above signals and calculates the depth deviation $e$. Then, the neuro-fuzzy controller calculates the command value of the electro-hydraulic proportional valve which adjusts the plowing depth of the implement.

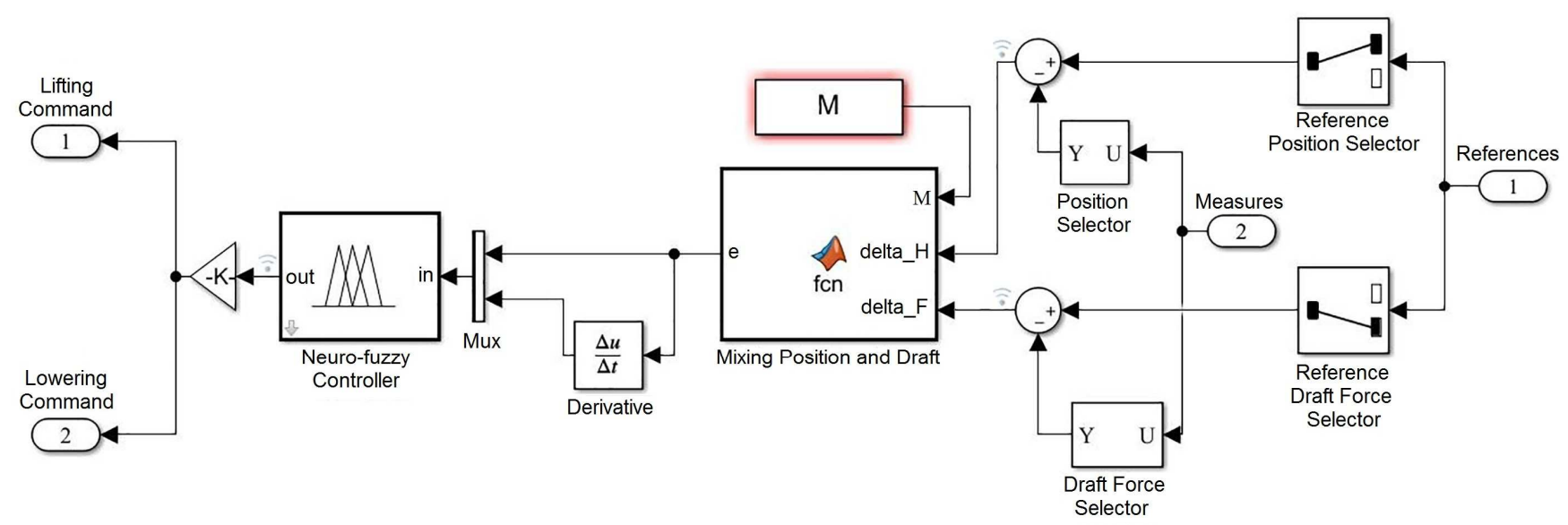

Fig. 5 Schematic diagram of the neuro-fuzzy controller with mix draft-position strategy

\subsection{The proposed adaptive neuro-fuzzy controller design}

In MATLAB software, the ANFIS editor graphical user interface is available in neuro-fuzzy designer app. Firstly, in Simulink environment, a Proportional Integral Derivative (PID) controller is designed and applied to the system in order to obtain the input and output data sets for training ANFIS. Oksanen, Eriksson, and Mikkola [15] proposed the practical method for tuning a PID hitch controller. Two modes of control are considered: upwards and downwards with different parameters. These parameters are summarized in Table 3.

Table 3 Parameters of the PID controller

\begin{tabular}{|c|c|c|}
\hline Parameter & Upward & Downward \\
\hline $\mathrm{k}_{\mathrm{p}}$ & 1.22 & 0.612 \\
\hline $\mathrm{K}_{\mathrm{i}}$ & 0 & 0 \\
\hline $\mathrm{K}_{\mathrm{d}}$ & 0 & 0.174 \\
\hline
\end{tabular}

The data set consists of the error in depth (e), the change in error (ce), and the controller output. Using the given input/output data set, the toolbox constructs a Fuzzy Inference System (FIS) whose membership function parameters are adjusted using a hybrid least-squares and back-propagation gradient descent algorithm method. This allows the fuzzy systems 
to learn from the data they are modeling. After several training processes with 20 epochs, a suitable neuro-fuzzy controller is obtained for tillage operations. A computing flowchart of ANFIS is provided in Fig. 6. The data set is a three-dimensional vector. $70 \%$ of the data are used for training, $15 \%$ are used for testing, and $15 \%$ are used for verification. The controller has seven membership functions for the two inputs with 49 rules, and the Gaussian combination membership functions have been chosen for fuzzification. After training, the error tolerance is close to zero as shown in Fig. 7, and the membership functions using grid method are shown in Fig. 8. Note that the input data have been normalized in the range of -1 to 1 .

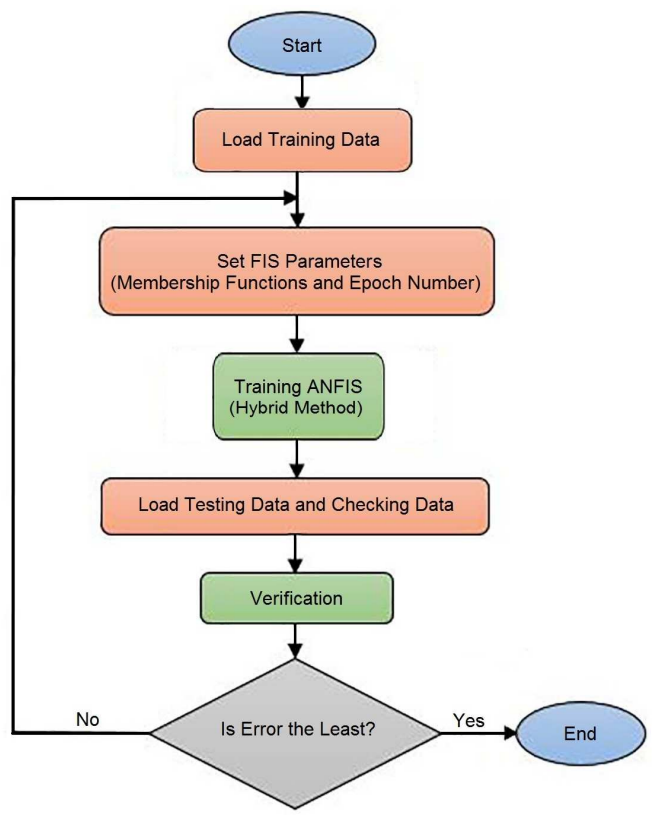

Fig. 6 Computing flowchart of the ANFIS model

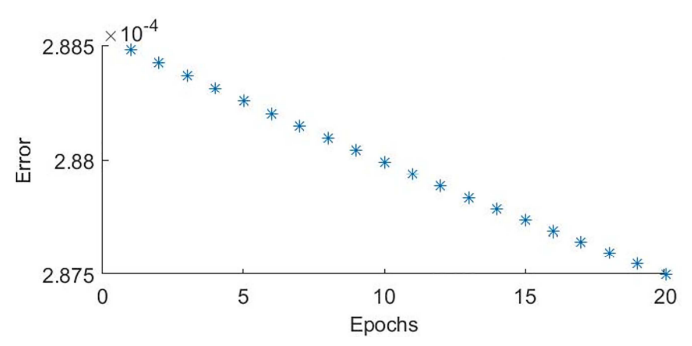

Fig. 7 Training error of the proposed ANFIS

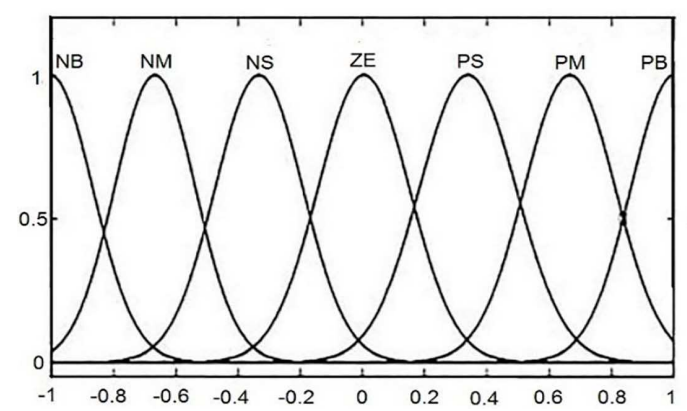

(a) $\operatorname{Error}(\mathrm{e})$

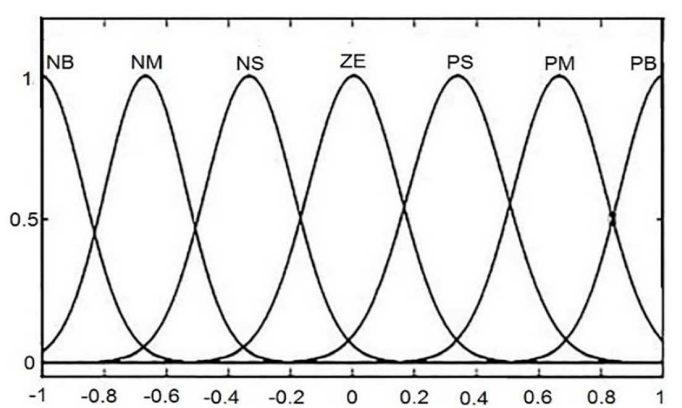

(b) Change in error (ce)

Fig. 8 Membership functions after training

\section{Results and Discussion}

The graphs in Figs. 9-11 show the positions of the chisel plow under PID and neuro-fuzzy control, for different value of mix coefficient $(M=0, M=0.25$, and $M=0.5)$. At the instants $t=0 \mathrm{~s}$ and $t=55 \mathrm{~s}$, the implement starts from the upper position. The mechanism takes some time to attend the desired upper position $(20 \mathrm{~cm})$ because lifting speed of the hitch mechanism is limited by the hydraulic power system. Then, a lowering signal is applied at $\mathrm{t}=5 \mathrm{~s}$, and the implement penetrates progressively 
under the soil until the desired depth $(30 \mathrm{~cm})$. The more the value of the coefficient $\mathrm{M}$ increases, the implement becomes more sensitive to soil resistance. This is beneficial for preventing tractor slippage and reducing fuel consumption. However, for large values of the mixing coefficient $(M>0.5)$, the implement moves away from the desired depth.

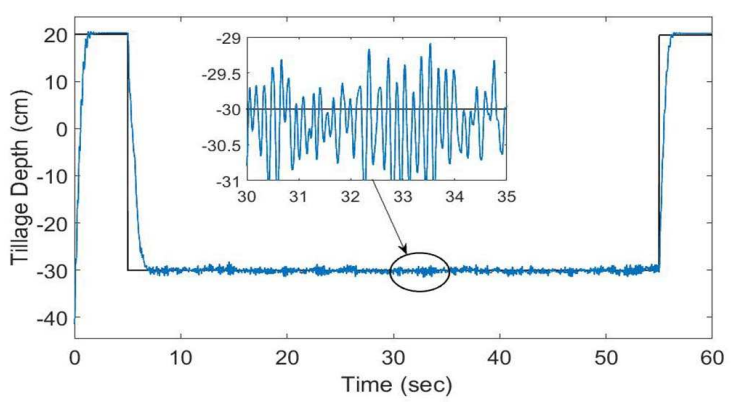

(a) PID

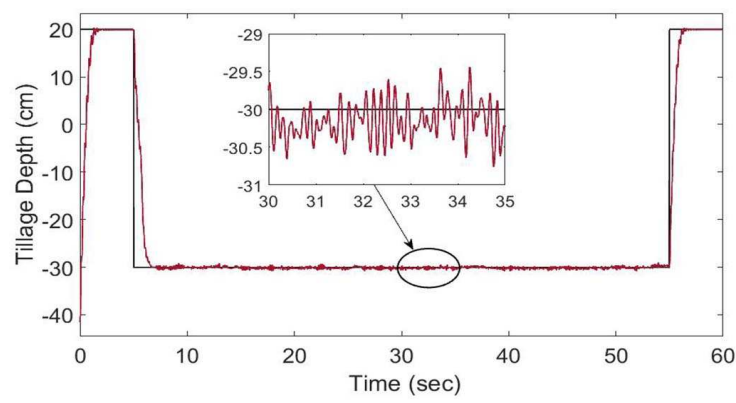

(b) Neuro-fuzzy

Fig. 9 Position of the chisel plow for $\mathrm{M}=0$

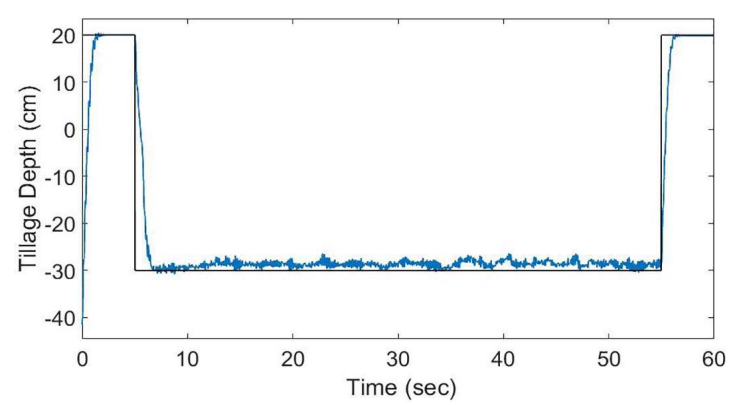

(a) PID

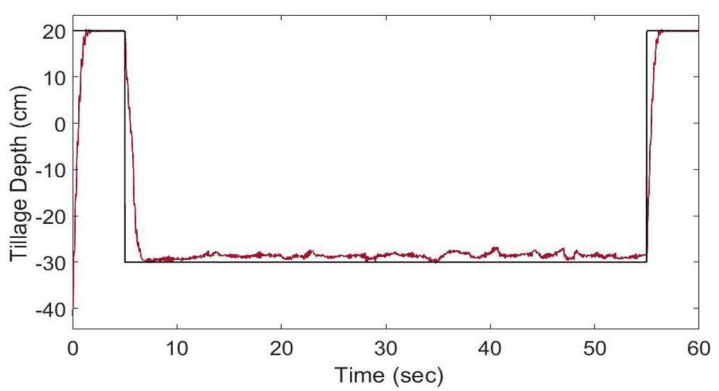

(b) Neuro-fuzzy

Fig. 10 Position of the chisel plow for $\mathrm{M}=0.25$

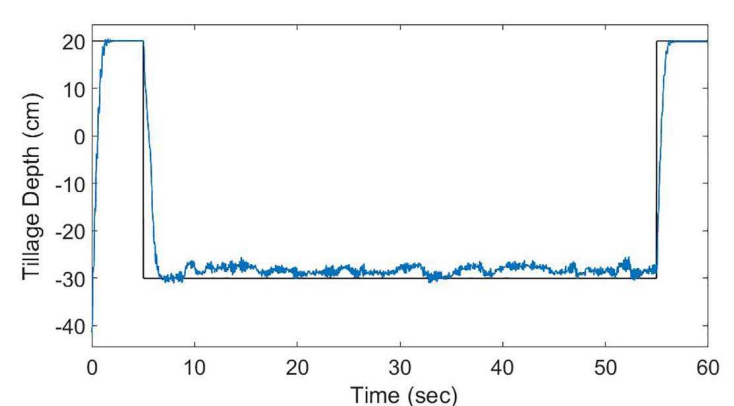

(a) PID

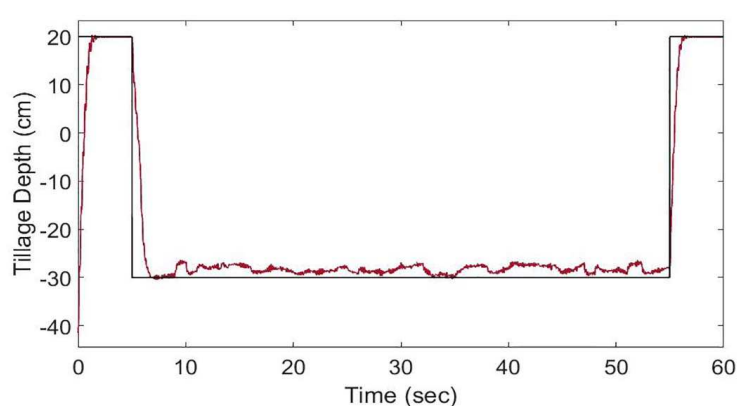

(b) Neuro-fuzzy

Fig. 11 Position of the chisel plow for $\mathrm{M}=0.5$

The graphs in Fig. 12 show the positions of the moldboard under PID and neuro-fuzzy control, for different values of the mix coefficient $(M=0, M=0.25$, and $M=0.5)$. Between $t=10 \mathrm{~s}$ and $t=60 \mathrm{~s}$, the implement follows the desired depth $(10 \mathrm{~cm})$. Note that for a small plowing depth, increasing the $\mathrm{M}$ coefficient does not have a significant effect on the desired depth. This is due to the fact that, at shallow plowing depths, soil resistances are reduced.

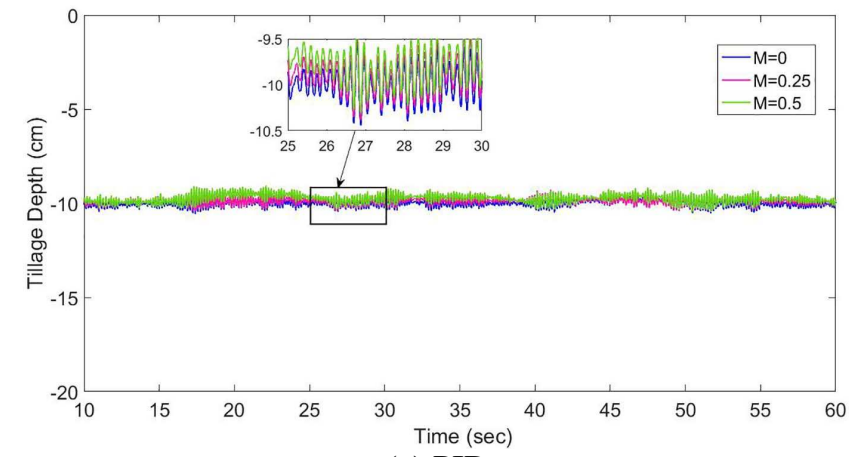

(a) PID

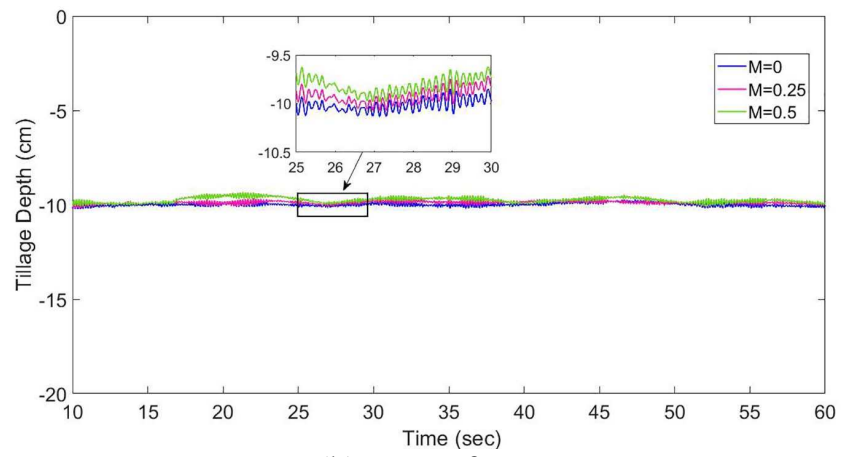

(b) Neuro-fuzzy

Fig. 12 Position of the moldboard plow 
In this work, the well-known Integral Time Absolute Error (ITAE) objective function is used to evaluate the proposed controller. The ITAE criterion is defined by:

$$
\text { ITAE }=\int_{0}^{\infty} t|e(t)| d t
$$

Table 4 Performance of the different controllers

\begin{tabular}{|c|c|c|c|c|c|c|c|}
\hline Implement & Controller & M value & Depth mean & Min & Max & Standard deviation & ITAE \\
\hline \multirow{6}{*}{ Chisel plow } & \multirow{3}{*}{ Neuro-fuzzy } & $\mathrm{M}=0$ & 29.88 & 29.07 & 30.85 & 0.25 & 0.32 \\
\hline & & $\mathrm{M}=0.25$ & 28.68 & 27.01 & 30.23 & 0.54 & 2.02 \\
\hline & & $\mathrm{M}=0.5$ & 28.29 & 26.43 & 30.28 & 0.64 & 2.45 \\
\hline & \multirow{3}{*}{ PID } & $M=0$ & 29.47 & 28.92 & 31.61 & 0.45 & 0.76 \\
\hline & & $\mathrm{M}=0.25$ & 27.96 & 26.9 & 30.70 & 0.77 & 2.27 \\
\hline & & $\mathrm{M}=0.5$ & 27.67 & 26.22 & 30.96 & 0.78 & 2.71 \\
\hline \multirow{6}{*}{ Moldboard plow } & \multirow{3}{*}{ Neuro-fuzzy } & $\mathrm{M}=0$ & 9.94 & 9.66 & 10.18 & 0.09 & 0.11 \\
\hline & & $\mathrm{M}=0.25$ & 9.84 & 9.51 & 10.23 & 0.11 & 0.41 \\
\hline & & $\mathrm{M}=0.5$ & 9.69 & 9.23 & 10.08 & 0.17 & 0.65 \\
\hline & \multirow{3}{*}{ PID } & $\mathrm{M}=0$ & 9.93 & 9.28 & 10.52 & 0.20 & 0.23 \\
\hline & & $\mathrm{M}=0.25$ & 9.83 & 9.15 & 10.52 & 0.21 & 0.63 \\
\hline & & $\mathrm{M}=0.5$ & 9.68 & 8.95 & 10.34 & 0.25 & 0.86 \\
\hline
\end{tabular}

Table 4 shows the comparative analysis between the proposed neuro-fuzzy controller and the PID controller. From Table 4, the following remarks and interpretations are deduced. For different values of $\mathrm{M}$, in the case of neuro-fuzzy controller, the depth mean value is near to the desired depth compared to the PID controller. For the chisel plow, the value of ITAE is 0.32 , for $\mathrm{M}=0$, in the case of the neuro-fuzzy controller; which is almost half of the PID controller. In addition, the standard deviations on the desired depth for different $\mathrm{M}$ values are shown in Table 4. It appears that, the standard deviation values for the proposed controller are lower than those obtained by the PID controller. These parameters shows that the system offers a great robustness toward the load perturbations and a better stability using the neuro-fuzzy controller rather than the PID controller.

\section{Conclusions}

This research presented an adaptive neuro-fuzzy controller for tractor's tillage operations. The design of this controller was carried out under MATLAB / neuro-fuzzy, after several attempts to arrive at an optimal architecture. Firstly, a CAD model of the three-point hitch system was designed under SolidWorks software. After that, the designed model was exported under MATLAB/Simscape Multibody. Then, an electro-hydraulic valve was simulated under MATLAB /Simscape Fluids to actuate the hitch-implement mechanism. Finally, the proposed controller was used in the system for the control of two implements hitched to the tractor. The performance index on ITAE indicates good responses in the case of neuro-fuzzy tillage depth controller which can replace other controllers. In the future, the proposed controller can be implemented in an agricultural tractor.

\section{Conflicts of Interest}

The authors declare no conflict of interest.

\section{References}

[1] B. Bhondave, T. Ganesan, N. Varma, R. Renu, and N. Sabarinath, "Design and Development of Electro Hydraulics Hitch Control for Agricultural Tractor," SAE International Journal of Commercial Vehicles, vol. 10, no. 1, pp. 405-410, 2017.

[2] J. Han, C. Xia, G. Shang, and X. Gao, "In-Field Experiment of Electro-Hydraulic Tillage Depth Draft-Position Mixed Control on Tractor,” IOP Conference Series: Materials Science and Engineering, vol. 274, no. 1, 012028, 2017.

[3] S. M. Shafaei, M. Loghavi, and S. Kamgar, "A Practical Effort to Equip Tractor-Implement with Fuzzy Depth and Draft Control System,” Engineering in Agriculture, Environment, and Food, vol. 12, no. 2, pp. 191-203, July 2019. 
[4] C. Liu, J. Zhao, J. Gu, Y. Du, Z. Li, Z. Zhu, et al., "Pressure Control Algorithm Based on Adaptive Fuzzy PID with Compensation Correction for the Tractor Electronic Hydraulic Hitch," Applied Sciences, vol. 10, no. 9, 3179 , May 2020.

[5] B. Haznedar and A. Kalinli, "Training ANFIS Structure Using Simulated Annealing Algorithm for Dynamic Systems Identification," Neurocomputing, vol. 302, pp. 66-74, August 2018.

[6] S. Subha and S. Nagalakshmi, "Design of ANFIS Controller for Intelligent Energy Management in Smart Grid Applications," Journal of Ambient Intelligence and Humanized Computing, vol. 11, no. 6, pp. 1-11, June 2020.

[7] J. S. Jang, “ANFIS: Adaptive-Network-Based Fuzzy Inference System,” IEEE Transactions on Systems, Man, and Cybernetics, vol. 23, no. 3, pp. 665-685, May-June 1993.

[8] V. Bakırcıoğlu, M. A. Şen, and M. Kalyoncu, "Adaptive Neural-Network Based Fuzzy Logic (ANFIS) Based Trajectory Controller Design for One Leg of a Quadruped Robot," 5th International Conference on Mechanics and Control Engineering, December 2016, pp. 82-85.

[9] H. Oubehar, A. Selmani, A. Ed-Dahhak, A. Lachhab, M. E. H. Archidi, and B. Bouchikhi, "ANFIS-Based Climate Controller for Computerized Greenhouse System," Advances in Science Technology and Engineering Systems Journal, vol. 5, no. 1, pp. 8-12, January 2020.

[10] R. Shanthi, S. Kalyani, and P. M. Devie, "Design and Performance Analysis of Adaptive Neuro-Fuzzy Controller for Speed Control of Permanent Magnet Synchronous Motor Drive,” Soft Computing, vol. 25, no. 2, pp. 1519-1533, January 2021.

[11] H. Bentaher, E. Hamza, G. Kantchev, A. Maalej, and W. Arnold, "Three Point Hitch Mechanism Instrumentation for Tillage Power Optimization,” Biosystems Engineering, vol. 100, no. 1, pp. 24-30, May 2008.

[12] Agricultural Wheeled Tractors-Rear Mounted Three-Point Linkage-Categories 1N, 1, 2N, 2, 3N, 3, 4N, and 4, GOST ISO 730-2019, 2020.

[13] Agricultural Machinery Management Data, ASAE D497.7, 2011.

[14] Bosch Rexroth AG, "Hitch Control Valves EHR5-OC, EHR5-LS, EHR23-EM2 RE," https://www.naptechniek.nl/images/catalogus/pdf/EHR23_re66125_2013-07.pdf, August 19, 2020

[15] L. Eriksson, T. Oksanen, and K. Mikkola, "PID Controller Tuning Rules for Integrating Processes with Varying Time-Delays," Journal of the Franklin Institute, vol. 346, no. 5, pp. 470-487, June 2009.

Copyright $\odot$ by the authors. Licensee TAETI, Taiwan. This article is an open access article distributed under the terms and conditions of the Creative Commons Attribution (CC BY-NC) license (https://creativecommons.org/licenses/by-nc/4.0/). 